\title{
A ORDEM PRONOMINAL \\ EM PORTUGUÊS BRASILEIRO: \\ DA ÊNCLISE À PRÓCLISE, \\ DO CLÍTICO AO TÔNICO \\ (OR THERE AND BACK AGAIN, \\ A WORD ORDER'S \\ HOLIDAY) ${ }^{1}$
}

\section{EL ORDEN PRONOMINAL EN PORTUGUÉS BRASILEÑO: DE LA ENCLISIS A LA PROCLISIS, DEL CLÍTICO AL TÓNICO (OR THERE AND BACK AGAIN, A WORD ORDER'S HOLIDAY)}

PRONOMINAL ORDER IN BRAZILIAN PORTUGUESE: FROM ENCLISIS TO PROCLISIS, FROM CLITIC TO TONIC (OR THERE AND BACK AGAIN, A WORD ORDER'S HOLIDAY)

Gabriel de Ávila Othero*

Rubia Wildner Cardozo**

Universidade Federal do Rio Grande do Sul

RESUMO: Investigamos as motivações gramaticais (i) para a mudança de ênclise para próclise em português brasileiro (PB), ocorrida em meados do século XIX, e (ii) para o uso do pronome tônico em função de objeto direto, observado atualmente em PB. A hipótese central que perseguiremos aqui é que o uso do pronome tônico e a consequente perda do clítico são uma tentativa de recuperar a ordem SVO, abandonada quando, em meados do século XIX, a próclise se fez categórica. Explicaremos o fenômeno na perspectiva da Teoria da Otimidade (TO), cf. Prince e Smolensky (1993), McCarthy e Prince (1993). A TO nos permitiu investigar as restrições envolvidas no fenômeno e a hierarquia dessas restrições (bem como sua mudança ao longo do tempo), algo essencial na explicação das alterações da colocação pronominal em PB. Concluímos que a implementação do pronome pleno como objeto se consolidou, primeiramente, com os pronomes de terceira pessoa (e com demais pronomes com características nominais, como você e a gente) e que a tendência na língua parece ser a estratégia de uso do tônico em função de objeto se generalize por todo o sistema pronominal.

PALAVRAS-CHAVE: Português brasileiro. Colocação pronominal. Pronomes. Objeto direto.

\footnotetext{
${ }^{1}$ Agradecemos aos colegas Athany Gutierres, Elisa Battisti, Marcos Goldnadel e Mônica Rigo Ayres pela leitura de versões preliminares do texto. Todas as inconsistências que o texto apresenta, contudo, são de nossa responsabilidade.

* Professor Adjunto do Instituto de Letras da Universidade Federal do Rio Grande do Sul - UFRGS. E-mail: gabriel.othero@ufrgs.br.

** Doutoranda em Estudos da Linguagem pela Pontifícia Universidade Católica do Rio Grande do Sul - PUC-RS. E-mail: rubia.wildner@gmail.com.
} 
RESUMEN: Investigamos las motivaciones gramaticales (i) para el cambio de enclisis a proclisis en portugués brasileño (PB), ocurrido a mitad del siglo XIX, y (ii) para el uso del pronombre tónico en función de objeto directo, observado actualmente en PB. La hipótesis central que perseguiremos aquí es la de que el uso del pronombre tónico (y la pérdida del clítico) es un intento de recuperar el orden SVO, abandonado cuando, a mitad del siglo XIX, la proclisis se hizo categórica. Explicaremos el fenómeno en la perspectiva de la Teoría de la Optimidad (TO), cf. Prince e Smolensky (1993), McCarthy e Prince (1993). La TO nos ha permitido investigar las restricciones involucradas en el fenómeno y la jerarquía de esas restricciones (bien como su cambio a lo largo del tiempo), algo esencial en la explicación de las alteraciones de la colocación pronominal en PB. Concluimos que la implementación del pronombre pleno como objeto se haya consolidado, primeramente, con los pronombres de tercera persona (y con los pronombres con características nominales, como "você" y "a gente") y que la tendencia parece ser que la estrategia de uso del tónico en función de objeto se generalice por todo el sistema pronominal.

PALABRAS CLAVE: Portugués brasileño. Colocación pronominal. Pronombres. Objeto directo.

ABSTRACT: We investigate the grammatical motivations (i) behind the change from enclisis to proclisis that took place during the nineteenth century in Brazilian Portuguese, and (ii) behind the increase of the tonic pronoun as a verbal complement. The central hypothesis here is that the tonic pronoun (and the consequent lost of the clitic) is an attempt to recover the SVO order in Brazilian Portuguese that was abandoned when, by the nineteenth century, proclisis became categorical: $\mathrm{SO}_{\text {clitic }} \mathrm{V}$. We explain the phenomenon within the Optimality Theory (OT) framework (PRINCE; SMOLENSKY 1993; MCCARTHY; PRINCE, 1993). OT allowed us to investigate the constraints involved in this phenomenon, and the hierarchy for these constraints (as well as the change of this hierarchy over time), and that was a crucial point to explain the changes of pronominal collocation in BP. We conclude that the implementation of the tonic pronoun as direct object has been consolidated first with third person pronouns (and with 'nominal pronouns', such as "você" and "a gente"), and that the tendency, we believe, is for this strategy to generalize for all other pronouns in BP.

KEYWORDS: Brazilian Portuguese. Pronominal collocation. Pronouns. Direct object.

\section{INTRODUÇÃO}

Neste artigo, investigamos as regras de colocação pronominal em PB. Na verdade, mais do que isso: estamos interessados em explicar as regras de colocação pronominal da gramática do $\mathrm{PB}$ no que diz respeito aos pronomes que funcionam como complemento verbal, tanto no caso de pronomes clíticos como no caso de pronomes tônicos (ou plenos) - vide exemplos (1) e (2) abaixo. Para alcançar esse objetivo, apresentaremos algumas condições (ou princípios) gramaticais que levam os pronomes clíticos a figurarem predominantemente em posição pré-verbal (posição proclítica), enquanto os pronomes tônicos, supostamente "nominativos" (pois desempenham tradicionalmente a função de sujeito do verbo), passam a receber o status de pronome "acusativo", aparecendo na posição de complemento verbal típica em PB, a posição pós-verbal.

Exploraremos o fato de que a gramática do PB apresenta, basicamente, três estratégias para o preenchimento da posição de objeto direto anafórico (e exofórico): (i) com um pronome clítico (exemplo 1); (ii) com um pronome tônico (exemplo 2); ou (iii) com um objeto nulo (exemplo 3$)^{2}$ :
(1) A: Você viu a Maria?
B: Sim, eu $a$ vi ontem.
(2) A: Você viu a Maria?
B: Sim, eu vi ela ontem.

\footnotetext{
${ }^{2}$ Não falaremos aqui sobre o objeto nulo (ON) em PB. A literatura sobre o ON em PB é abundante (cf., entre outros, DUARTE, 1989; GALVES, 1989; CYRINO, 1993, 1994, 2003; SCHWENTER; SILVA, 2002; CASAGRANDE, 2007, 2012; PANTIZ, 2015, entre outros). Também não nos interessam aqui os casos em que temos um sintagma nominal como objeto, pois nosso foco neste texto está no quadro pronominal do PB.
} 


\section{(3) A: Você viu a Maria? \\ B: Sim, eu vi Ø ontem.}

Não lidaremos com a estratégia (iii); investigaremos apenas as estratégias (i) e (ii) e sua concorrência. Ou seja, abordaremos o uso de clíticos e de pronomes tônicos como complementos. Na verdade, a estratégia (i) está perdendo espaço para os pronomes plenos e objetos nulos, pelo menos no que toca a retomada anafórica de 3 a pessoa (DUARTE, 1989; CYRINO, 1994, 1996; MONTEIRO, 1994, NUNES, 1996, entre outros). Entretanto, é ainda uma estratégia amplamente usada com clíticos de primeira e segunda pessoas, me e te, especialmente (cf. MONTEIRO, 1994; SCHWENTER; SILVA, 2002, por exemplo).

O que nos interessa, em específico, é explicar, formalmente - por meio de análises de restrições ranqueáveis -, por que usamos o pronome clítico na posição pré-verbal (posição proclítica) ${ }^{3}$ e por que usamos o pronome tônico na posição pós-verbal ${ }^{4}-$ como $^{2}$ ilustramos com os exemplos (1) e (2) acima.

Acreditamos que a diferença na ordem dos complementos verbais pronominais (clíticos vs. tônicos) tem relação com a ordem de superfície da frase em PB. Sabemos que, em um determinado momento de sua história (até a metade do século XIX), o PB manifestou a ênclise como regra generalizada de colocação pronominal, mantendo, assim, a ordem superficial SVO ${ }^{5}$. Em um momento posterior (a partir da segunda metade do século XIX), a regra de colocação do clítico passou a ser a próclise, acarretando uma mudança na ordem superficial da frase, que passou de SVO para SOV nas construções pronominais (como aparece no exemplo $1)^{6}$. Finalmente, em um terceiro momento, no PB atual (séculos XX e XXI), o sistema parece estar tentando recuperar a aparente ordem SVO - não pelo recurso da ênclise pronominal (como acontece em português europeu (PE), por exemplo), mas pela "substituição" do tipo de pronome que pode desempenhar a função de objeto direto do verbo: ao invés de usarmos clíticos em posição pós-verbal, passamos a aceitar pronomes plenos nessa posição.

As ideias básicas que exploraremos aqui, na verdade, não são nossas. Por isso, deixamos aqui algumas advertências:

a. apesar de a estratégia mais comum na retomada anafórica de objetos diretos de terceira pessoa ser a estratégia que apontamos em (iii) ${ }^{7}$, as estratégias (i) e (ii) também fazem parte do "repertório" da gramática do PB - vide a gramaticalidade dos exemplos (1) e (2);

b. no caso da estratégia (i), o PB reservou a posição pré-verbal para as formas pronominais clíticas (cf. referências da nota 3);

c. no caso da estratégia (ii), o PB reservou a posição pós-verbal para as formas pronominais plenas (cf. referências da nota 4$)$.

Nossa contribuição com este texto é (i) mostrar a interação entre as condições gramaticais que atuam sobre (b) e (c) e formalizar essas condições em ranqueamentos; e (ii) defender que (c) (e não (b) ou a manutenção das estratégias (b) e (c)) será a regra categórica em PB, a longo prazo - caso nossa hipótese se mostre correta, i.e., o PB "busca" uma estratégia de manutenção da ordem SVO. Formalizaremos nossas análises com as ferramentas da Teoria da Otimidade (cf. PRINCE; SMOLENSKY,1993; MCCARTHY; PRINCE, 1993).

\footnotetext{
${ }^{3}$ Cf. Pereira (1981), Pagotto (1996), Galves (2001), Vieira (2002, 2003), Brisolara (2008), Castilho (2010), Perini (2016), entre outros.

${ }^{4}$ Cf. Omena (1978), Kato (2002), Castilho (2010), Perini (2016), entre outros.

${ }^{5}$ Cf. Pagotto $(1993,1996)$, Nunes (1996), entre outros.

${ }^{6}$ Cf. referências da nota 5 .

${ }^{7} \mathrm{Na}$ comparação entre as três estratégias que elencamos aqui (a saber: retomada com o clítico, retomada com pronome tônico e retomada com objeto nulo); cf. Cyrino (1993), Schwenter e Silva (2002) e Ayres (2016). A retomada do objeto em PB também pode ser feita - e é, muitas vezes - com um sintagma nominal - cf. Monteiro (1994), Vieira-Pinto e Coelho (2016).
} 


\section{PB DA PRIMEIRA METADE DO SÉCULO XIX}

Ao longo da história do PB, observou-se certa mobilidade de colocação dos clíticos (cf. Pagotto 1993, Nunes 1996, Cyrino 1997, Castilho 2010). A mudança na direção de cliticização, conforme Castilho (2010: 303), "se deu a partir da segunda metade do século XIX, época em que Cyrino (1997) encontrou as primeiras ocorrências de próclise a imperativo afirmativo”. O PB da primeira metade do século XIX privilegiava a ênclise como regra de colocação pronominal dominante. Mostraremos, nesta seção, o princípio gramatical básico envolvido na colocação pronominal em português à época, quando o PB era uma língua que privilegiava a ênclise. Ou seja, entre (a) e (b), abaixo, a estratégia empregada em (b) representa a regra padrão da época.
(4) A Maria viu o João ontem?
a) Sim, a Maria o viu.
b) Sim, a Maria viu-o.

Acreditamos que há, basicamente, um princípio gramatical sobre a organização da ordem frasal básica da estrutura de superfície da língua envolvido aqui. Trata-se de uma restrição sobre a ordem canônica, não marcada, entre os elementos sujeito, verbo e complementos. Tal restrição é conhecida na literatura como STAY

\section{STAY: movimentos não são permitidos? .}

STAY é uma restrição que diz que não se devem movimentar elementos dentro da frase, ou seja, "mantenha a ordem sintática básica das sentenças da língua" (OTHERO; MENUZZI 2009, p. 39). Considerando que o português é uma língua classificada tipologicamente como $\mathrm{SVO}^{10}$, o tableau de análise para os candidatos em (4) pode ser assim apresentado ${ }^{11}$ :

A Maria viu o João ontem? ${ }^{12}$

\begin{tabular}{c|c} 
& STAY \\
\hline a. A Maria o viu. & $*$ \\
\hline b. A Maria viu-o. & \\
Tableau 1 &
\end{tabular}

No Tableau 1, o candidato (a) viola a restrição STAY (assinalamos a violação com um asterisco), já que não apresenta a ordem superficial da frase SVO. O candidato (b), ao contrário, respeita STAY, sendo o candidato ótimo a output em uma língua que privilegia a ênclise. Porém, é muito difícil apontar um candidato vencedor levando-se em conta apenas uma restrição. É interessante mostrar as restrições interagindo para que possamos, mais tarde, observar justamente como se dá a mudança em curso - através de uma reorganização do ranqueamento das restrições em jogo, como argumentaremos.

\footnotetext{
${ }^{8}$ Restrição baseada em Grimshaw (1997), Costa (2001), Othero e Menuzzi (2009) e Othero e Figueiredo Silva (2012).

${ }^{9} \mathrm{Ou}$, de maneira mais formal: atribua uma marca de violação para cada elemento que não seguir a ordem canônica da língua.

${ }^{10}$ Cf. Neves (2000), Dryer (2005), Kenedy (2013).

${ }^{11} \mathrm{Na}$ verdade, este não é, de fato, um tableau de análise, pois há apenas uma única restrição (portanto, não há competição entre as restrições). Mantemos o tableau aqui para fins ilustrativos, como uma maneira de o leitor começar a se familiarizar com os próximos tableaux (esses sim, tableaux de fato) que apresentaremos. Agradecemos à Athany Gutierres e à Elisa Battisti por essa observação.

${ }^{12}$ Não mostraremos o input das análises aqui por não nos parecer essencial. Imaginamos que o input de nossas análises seja uma forma sintática subjacente do tipo SVO. Daí Stay ser uma restrição de fidelidade input/output. Como afirmam Othero e Menuzzi (2009, p. 29), "[e]m sintaxe TO, as análises comumente assumem que o input contém uma representação do 'conteúdo proposicional' de uma sentença - isto é, informação especificando os predicadores da frase, seus argumentos etc. bem como alguma informação de natureza pragmática, como a função discursiva dos diferentes elementos do conteúdo proposicional [...]”.
} 
Por isso, buscamos na literatura outra restrição gramatical que influenciou - e influencia - a colocação pronominal em português. Essa restrição diz respeito à direção de cliticização nas línguas, ou seja, é um princípio gramatical de caráter sintático-prosódico que influencia o processo de adjunção clítico-núcleo.

DireÇão De CliticIZAÇão (DiRCL): a direção do clítico pronominal verbal é da esquerda para a direita ${ }^{13-14}$.

Essa restrição afirma que o clítico deve anteceder o verbo (cf. NUNES, 1996) para argumentação a respeito. Com essa restrição em jogo, analisamos novamente nossos candidatos a output.

A Maria viu o João ontem?

\begin{tabular}{c|c|c} 
& STAY & DIRCL \\
\hline a. A Maria o viu. & ${ }^{*} !$ & \\
\hline b. A Maria viu-o. & & $*$ \\
& &
\end{tabular}

No Tableau 2, candidato (b) é o candidato ótimo, uma vez que viola apenas a restrição mais baixa na hierarquia, enquanto o candidato (a) viola a restrição mais alta - uma violação fatal, portanto (marcamos essa violação fatal com um ponto de exclamação). Essa informação é importante, pois vemos que há um princípio gramatical (DIRCL) que, em um momento da língua, não foi importante; ou melhor: foi menos importante do que um princípio sobre a manutenção da organização sintática linear canônica da língua.

Mostramos apenas análises com o pronome $o$. Poderíamos ter apresentado, mutatis mutandis, análises com qualquer outro clítico pronominal. Mostramos, abaixo, uma análise com o clítico me, apenas para fins ilustrativos, já que a análise de todos os clíticos repetirá o que encontramos no Tableau 2:

Quem a Maria viu ontem?

\begin{tabular}{c|c|c} 
& STAY & DIRCL \\
\hline a. A Maria me viu. & ${ }^{*} !$ & \\
\hline b. A Maria viu-me. & & $*$ \\
\multicolumn{2}{|c|}{ Tableau 3} &
\end{tabular}

Conhecemos agora (parcialmente) o ranqueamento das restrições: em uma língua que privilegia a ênclise como estratégia padrão de colocação pronominal (como foi o caso do português em períodos anteriores), o princípio de direção de cliticização, tal como formulado aqui, é dominado por STAY. A hierarquia que propomos é, então, a seguinte:

PB até metade do século XIX:

(5) STAY $>$ DIRCL

Vejamos, na próxima seção, o português da segunda metade do século XIX e do século XX.

\footnotetext{
${ }^{13}$ Restrição baseada em Nunes (1996).

${ }^{14} \mathrm{Ou}$, de maneira mais formal: atribua uma marca de violação para cada pronome clítico que não apresentar ordem proclítica.
} 


\section{O PB DA SEGUNDA METADE DO SÉCULO XIX E DO SÉCULO XX}

Sabemos que, pelo menos desde a segunda metade do século XIX, a tendência geral do PB, no que tange à colocação pronominal, é a próclise (cf. várias referências já citadas, além de gramáticas contemporâneas que lidam, de fato, com dados do PB, como PERINI, 2002, 2016; CASTILHO, 2010; BAGNO, 2011). Trata-se da estratégia (i) que elencamos na primeira seção do texto. Entretanto, como mencionamos, também na primeira seção, temos outra estratégia de retomada anafórica (ou exofórica) pronominal: trata-se do uso de um pronome tônico em posição de objeto - a estratégia (ii) que mencionamos acima. Comecemos lidando com a estratégia (i) e revejamos o ranqueamento que propusemos na seção anterior.

\subsection{ESTRATÉGIA (I): PRÓCLISE}

Dissemos que acreditávamos que a mudança ênclise > próclise iria refletir um reordenamento das restrições no ranking da gramática da língua. Então, se tínhamos o ranking STAY >> DIRCL para uma língua que privilegiava a ênclise, temos de repensar esse ranqueamento agora, para lidar com o fato de que o candidato (a) é o candidato ótimo a output em PB contemporâneo:

(6) Quem a Maria viu ontem?

a) A Maria me viu.

b) A Maria viu-me.

Ou seja, agora o candidato ótimo é aquele que apresenta uma estratégia de cliticização da esquerda para a direita, como aponta Nunes (1996). Entretanto, essa mudança na direção de cliticização tem um custo: a ordem de superfície da estrutura, que seguia a ordem canônica SVO, passa a ser SOV sempre que tivermos um clítico em jogo. Em outras palavras: essa alteração na direção de cliticização ocasionou uma ruptura aparente na organização canônica da frase em PB.

Em sendo assim, somos autorizados a propor que o ranqueamento do PB seja o seguinte:

\section{(7) DIRCL $>>$ STAY}

Ou seja: a restrição DIRCL é elevada à condição mais importante no ranqueamento que propusemos, e isso nos permite analisar (6) com o seguinte tableau:

Quem a Maria viu ontem?

\begin{tabular}{c|c|c} 
& DIRCL & STAY \\
\hline b. A Maria viu-me. & ${ }^{\star}$ a & \\
\hline b. A &
\end{tabular}

Tableau 4

O candidato ótimo é, agora, aquele que apresenta ordem proclítica, e não mais aquele que apresenta ordem enclítica. Assim, podemos argumentar que, a partir da segunda metade do século XIX, houve uma reorganização das restrições da hierarquia do PB, em que a direção da cliticização (DIRCL) passou a ser mais importante do que a manutenção da ordem canônica SVO (STAY), como apontam as análises nos tableaux. A próclise é, agora, a regra geral do PB (cf. referências já citadas).

\subsection{ESTRATÉGIA (II): PRONOMES PLENOS}

Como mencionamos anteriormente, há uma clara tendência, em PB, de eliminação dos pronomes clíticos (cf. referências já citadas). Vimos que, em seu lugar, duas estratégias vêm ganhando espaço: o objeto anafórico nulo e o uso de pronomes plenos. Também já 
alertamos para o fato de que não lidaremos com o objeto nulo neste texto ${ }^{15}$; então, passemos a discutir os casos em que um pronome pleno ocupa a posição de complemento do verbo.

Antes de passarmos às análises, temos uma advertência: quando dissemos que os clíticos estão perdendo espaço, dissemos apenas uma parte da verdade. Os clíticos que perderam seu espaço em português foram apenas os clíticos de $3^{a}$ pessoa, especialmente em suas formas sem onset silábico ( $o, a$, os, as) - cf. Nunes (1996) e outros; em seu lugar, atestamos usos mais frequentes das formas plenas (ele, ela, eles, elas $)^{16}$. Os demais clíticos $(m e$, te, nos), como argumentaremos na sequência, estão em concorrência com formas tônicas, como veremos.

Façamos uma última advertência aqui: lidaremos com dois tipos de pronomes: os pronomes de fato, com características fonomorfológicas "tradicionais" (são monossilábicos, apresentam forma reta e oblíqua, etc.) e os pronomes atípicos, que apresentam características fonomorfológicas típicas de substantivos (como a flexão em gênero e número). Por isso, resolvemos classificar os pronomes com os quais efetuaremos nossas análises nesses dois grupos, justamente: o dos pronomes de fato - eu, tu, nós e seus respectivos clíticos, me, te e nos - e o dos pronomes com características nominais - vocêe, ele, a gente e seus respectivos plurais, no caso dos dois primeiros (vocês e eles). As análises seguem fazendo essas distinções.

\subsubsection{OS PRONOMES COM CARACTERÍSTICAS NOMINAIS}

Comecemos com o segundo grupo de pronomes. Como mencionamos acima, os pronomes do PB apresentam diferenças formais entre si. Algumas dessas diferenças já foram analisadas por Mattoso Camara Jr., inclusive. Por exemplo, os pronomes de $1^{\text {a }}$ e $2^{\text {a }}$ pessoa, conforme observado em Camara Jr. (1972), apresentam plurais heteronímicos e não têm gênero, ao contrário do pronome de $3^{\mathrm{a}}$ pessoa, que, se assemelhando aos nomes, apresenta flexão de gênero e de número $($ ele $+\mathrm{a}=$ ela; ele $+\mathrm{s}=$ eles $)$. E poderíamos incluir, nesse mesmo "paradigma de flexão verbal" de $3^{\text {a }}$ pessoa, as formas pronominais relativamente inovadoras em $\mathrm{PB}$ você e $a$ gente. Assim como ele, essas formas também flexionam o verbo na $3^{a}$ pessoa do singular e também apresentam características mais "nominais" do que "pronominais": são formas tônicas com mais de uma sílaba (ao contrário de eu, tu e nós, monossilábicos) e têm sua história de gramaticalização relativamente recente e bem registrada na língua, sendo resultados de processos de gramaticalização que ocorreram com pronomes demonstrativos (no caso de ele, cf. CAMARA JR., 1972; BAGNO, 2011), com pronomes de tratamento (no caso de você, cf. FARACO,1996; VITRAL, 1996; BASSO; GONÇALVES, 2014) ou com um sintagma nominal (no caso de a gente, cf. OMENA, 1986; LOPES, 2003).

Além disso, como mostraremos aqui, esse tipo de pronome (com características nominais) perdeu a distinção formal entre suas formas nominativa e acusativa. É o que mostramos no quadro 1.

\begin{tabular}{c|c} 
Quadro 1: Pronomes com características nominais em suas formas nominativa e acusativa \\
Forma nominativa & Forma acusativa \\
\hline Você - Você viu a Maria & Você - A Maria viu você \\
\hline Ele - Ele viu a Maria & Ele - A Maria viu ele \\
\hline A gente - A gente viu a Maria & A gente - A Maria viu a gente
\end{tabular}

Compare esse quadro com o quadro 2, contendo o paradigma de caso morfológico dos pronomes de fato (eu, tu, nós). Apenas esses pronomes apresentam ainda contraste significativo e frequente entre suas formas nominativas e acusativas:

\footnotetext{
${ }^{15}$ Tratamos sobre o objeto nulo em outros textos, como Ayres e Othero (2016), Othero et al. (2016), Othero e Schwanke (a sair) e Othero e Spinelli (a sair).”.

${ }^{16}$ Outro clítico que perdeu espaço foi o de segunda pessoa do plural, vos - juntamente com sua contrapartida tônica, vós. Em seu lugar, adotamos vocês ou cês (cf. gramáticas recentes do PB, como as já mencionadas PERINI, 2002, 2016; CASTILHO, 2010 e BAGNO, 2011, por exemplo).
} 
Quadro 2: Pronomes de fato em suas formas nominativa e acusativa

\begin{tabular}{c|c} 
Forma nominativa & Forma acusativa \\
\hline Eu - Eu vi a Maria & Me - A Maria me viu \\
\hline Tu - Tu viu a Maria & Te - A Maria te viu \\
\hline Nós - Nós vimos a Maria & Nos - A Maria nos viu
\end{tabular}

Em resumo, estamos dizendo que podemos agrupar os pronomes pessoais do PB em duas classes naturais. A classe que estamos analisando nesta seção (a dos pronomes com características nominais) apresenta as seguintes características formais:

1. tem mais de uma sílaba;

2. sofre flexão nominal;

3. leva o verbo a ser flexionado na $3^{\text {a }}$ pessoa do singular;

4. diacronicamente, é composta por formas que resultaram de processos de gramaticalização "recentes";

5. tem formas sincréticas para o caso nominativo e acusativo.

A principal característica desses pronomes para nossos objetivos é que suas formas nominativas e acusativas são idênticas. Isso aparecerá nas análises que formalizaremos em seguida. Imaginemos dois candidatos a output, da mesma forma como fizemos nas análises anteriores com os clíticos (Tableaux 1 a 4); um candidato traz o pronome objeto na posição pós-verbal (A Maria viu você), equivalente à posição enclítica (quando lidamos com clíticos), e o outro candidato traz o pronome objeto na posição pré-verbal, equivalente, mutatis mutandis, à posição proclítica (A Maria você viu):

Quem a Maria viu ontem?

\begin{tabular}{c|c|c} 
& DIRCL & STAY \\
\hline b. A Maria você/ele/a gente viu. & & \\
\hline \multirow{2}{*}{ a. Maria viu você/ele/a gente. } & & $*$
\end{tabular}

Tableau 5

Obviamente, o candidato ótimo aqui é o candidato (a) - as opções expressas em (b) são claramente agramaticais em PB. Nenhum candidato viola a restrição de DIRCL (uma vez que não há clíticos envolvidos aqui) e o candidato (b) viola a restrição STAY.

Conseguimos ver aqui que o ranqueamento que propusemos acima (DIRCL $>$ STAY) ainda se aplica. Ou seja: conseguimos apresentar um ranqueamento para explicar fases anteriores do português que privilegiavam a ênclise como regra default de colocação pronominal (vide (5)) e outro ranqueamento, contendo exatamente as mesmas duas restrições, que explica as estratégias de colocação pronominal em PB atual (vide (7)).

Dentro dessa estratégia de se usar pronomes plenos em posição de objeto, precisamos lidar com os pronomes de fato: eu, tu e nós. Queremos argumentar que o caminho desses pronomes deve seguir o mesmo rumo dos pronomes com características nominais, pelo menos no que diz respeito à sincretização das formas nominativa e acusativa. Isso porque, como já mencionamos, há vários trabalhos que apontam para uma tendência de "desaparecimento" dos clíticos em PB. Além disso, como tentaremos argumentar aqui, acreditamos que o princípio STAY seja decisivo para o funcionamento pronominal em PB. Em outras palavras, a língua busca manter a ordem superficial canônica SVO, como fora registrado outrora. Para fazer isso, a gramática da língua tem dois caminhos distintos que podem ser trilhados: (a) voltar à colocação pronominal enclítica e manter apenas pronomes clíticos na função de complemento verbal ou (b) abandonar os clíticos (que, como vimos, subvertem a ordem SVO em português contemporâneo) e atribuir a responsabilidade aos pronomes tônicos de servirem como pronomes nominativos e acusativos. Vejamos, na próxima seção, como isso pode funcionar.

\subsubsection{PRONOMES DE FATO (EU, TU, NÓS)}

Opondo-se aos pronomes analisados na seção anterior, os pronomes de fato formam uma classe natural com características formais distintas. Abaixo, apresentamos as características das duas classes de pronomes em um quadro comparativo. 
Quadro 3: comparação entre as duas classes de pronomes

\begin{tabular}{c|c} 
Pronomes de fato & Pronomes com características nominais \\
\hline São monossilábicos & Têm mais de uma sílaba \\
\hline Não sofrem flexão nominal & Plexion sofrer flexão nominal o verbo na $3^{\text {a }}$ pessoa \\
\hline $\begin{array}{c}\text { Flexionam o verbo em paradigma próprio }\left(1^{\mathrm{a}} \mathrm{e} 2^{\mathrm{a}} \text { pessoas, do }\right. \\
\text { singular ou plural })\end{array}$ & Diacronicamente são formas que resultaram de processos de \\
\hline gramaticalização "recentes"
\end{tabular}

Esses pronomes, como mencionamos em 3.1, aparecem em suas formas proclíticas ( $m e$, te, nos) quando na retomada anafórica ou exofórica em função de objeto direto - já explicamos esses casos no Tableau 4. Contudo, também encontramos suas formas retas na posição de objeto, como vemos nos exemplos a seguir:

(8) Beija eu, beija eu...

(9) A Maria viu tu ontem.

(10) A Maria viu nós na festa.

Ainda que estigmatizadas, tais construções são atestadas em PB atual e devemos explicá-las em nossas análises. Acreditamos que se trata de uma mudança no paradigma pronominal. Formalizamos a análise nos tableaux a seguir:

Quem a Maria viu ontem?

\begin{tabular}{c|c|c} 
& DIRCL & STAY \\
\hline b. A Maria viu eu/tu/nós. & & \\
\hline b. A Maria eu/tu/ele viu. & & $* !$
\end{tabular}

Entre os candidatos (a) e (b), o candidato (a) é o ótimo. O candidato (b) é agramatical em PB, ao passo que (a), como mencionamos, é gramatical, ainda que estigmatizado. No próximo tableau, unificamos as análises com os demais pronomes que aparecem em posição pós-verbal quando na função de objeto direto:

Quem a Maria viu ontem?

\begin{tabular}{c|c|c} 
& DIRCL & STAY \\
\hline b. A Maria eu/tu/você/ele/nós/a gente viu. & & \\
\hline Tableau 7 & & ${ }^{*} !$
\end{tabular}

Como podemos constatar, o ranqueamento já proposto explica tanto os casos de próclise (vide Tableau 4) como os casos em que os pronomes tônicos são complementos verbais em PB atual. Poderíamos parar, então, por aqui, mas gostaríamos de perseguir uma outra ideia: gostaríamos de ver a competição entre as formas clíticas e as plenas no caso dos pronomes de fato.

Dissemos que os pronomes com características nominais (você, a gente, ele) sincretizaram suas formas nominativa e acusativa. Agora, queremos ver até onde essa linha de raciocínio pode nos levar: e se essa tendência se generalizar para todos os pronomes? Ou seja, e se as formas clíticas forem abandonadas e a gramática do PB contar apenas com pronomes tônicos?

Há três vantagens aparentes nesse caminho: (i) o quadro pronominal se estabiliza mantendo apenas um tipo de pronome (a saber: os tônicos); (ii) todos os pronomes poderão atuar tanto como sujeito como objeto, já que podem desempenhar dupla função com a mesma forma; e (iii) a língua mantém sua forma não marcada SVO, mesmo quando usamos pronomes como complementos verbais. Veja abaixo: 
(i) Estabilização do quadro pronominal:

De

\begin{tabular}{c|c|c} 
Forma nominativa & Identidade morfológica & Forma acusativa \\
\hline eu & $\neq$ & me \\
\hline você & $=$ & você \\
\hline tu & $\neq$ & te \\
\hline ele & $\neq$ & ele \\
\hline nós & $=$ & nos \\
\hline a gente & $=$ & a gente \\
\hline vocês & $=$ & vocês \\
\hline eles & eles
\end{tabular}

Tabela 1: Quadro pronominal com pronomes tônicos e clíticos

poderia passar a

\begin{tabular}{c|c|c} 
Forma nominativa & Identidade morfológica & Forma acusativa \\
\hline eu & $=$ & eu \\
\hline você & $=$ & você \\
\hline tu & $=$ & tu \\
\hline ele & $=$ & ele \\
\hline nós & $=$ & nós \\
\hline a gente & $=$ & a gente \\
\hline vocês & $=$ & vocês \\
\hline eles & $=$ & eles
\end{tabular}

Tabela 2: Quadro pronominal apenas com pronomes tônicos

(ii) Sincretismo formal na interface com função sintática:

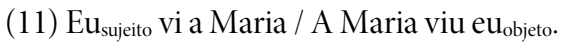

(12) Você $\hat{e}_{\text {sujeito viu a Maria / A Maria viu você }}$ objeto.

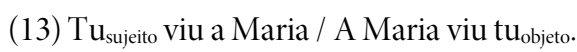

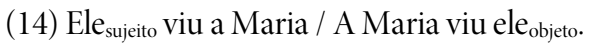

Etc.

(iii) Estrutura canônica SVO:

(15) A Maria viu o Pedro.

$$
\mathrm{S} \quad \mathrm{V} \quad \mathrm{O}
$$

(16) A Maria viu eu/você/tu/ele.

$\mathrm{S} \quad \mathrm{V} \quad \mathrm{O}$

Na verdade, vários estudos já apontam para a substituição de dois desses pronomes por outras formas pronominais (do grupo que estudamos em 3.2.1) no vernáculo do PB: tu está perdendo espaço para você, e nós está perdendo terreno para a gente (cf. MONTEIRO, 1994; MENON, 1995; LOPES, 1999, 2007, entre outros). Essa parece ser uma tendência que vem a favor da nossa hipótese de favorecer os pronomes que podem sincretizar as formas nominativa e acusativa. Nesse caso, ao invés de construções com tu e nós na função de objeto passarem a fazer parte do vernáculo da língua e perderem seu estigma marcado, essas formas podem simplesmente ser substituídas por outras que são aceitas em diversos registros e dialetos como formas sincréticas nominativo-acusativas (você e a gente) $)^{17}$.

\footnotetext{
${ }^{17}$ Ou seja: assumindo que a língua esteja buscando manter a ordem SVO, no caso dos pronomes tu e nós, o problema do estigma linguístico pode ser resolvido de duas maneiras: ou construções como A Maria viu tu e A Maria viu nós deixam de ser estigmatizadas e esses pronomes deixam de ser "marcadores" para se tornarem
} 
De qualquer maneira, queremos confrontar, em análises com restrições, as formas tônica e clítica desses três pronomes. Por isso, apresentamos, abaixo, análises em que os candidatos apresentam pronome tônico $v s$. pronome clítico. Mostraremos que, nessas "disputas", o tônico leva a melhor, considerando o ranqueamento proposto:

Quem a Maria viu ontem?

\begin{tabular}{c|c|c} 
& DIRCL & STAY \\
\hline a. A Maria viu eu. & & \\
\hline b. A Maria eu viu. & & ${ }^{*} !$ \\
\hline c. A Maria viu-me. & ${ }^{*} !$ & \\
\hline d. A Maria me viu. & & ${ }^{*} !$
\end{tabular}

Quem a Maria viu ontem?

\begin{tabular}{c|c|c} 
& DIRCL & STAY \\
\hline b. A Maria viu tu. & & \\
\hline b. A Maria tu viu. & & ${ }^{\star} !$ \\
\hline d. A Maria viu-te. & ${ }^{*}$ Maria te viu. & \multirow{2}{*}{$\begin{array}{c}{ }^{*} ! \\
\text { Tableau } 9\end{array}$}
\end{tabular}

Quem a Maria viu ontem?

\begin{tabular}{c|c|c} 
& DIRCL & STAY \\
\hline a. A Maria viu nós. & & $* !$ \\
\hline b. A Maria nós viu. & & \\
\hline c. A Maria viu-nos. & $* !$ & $* !$
\end{tabular}

O que tentamos mostrar, nos tableaux acima, foi a competição entre quatro formas possíveis a output quando temos um pronome na função de objeto direto em PB:

(a) um pronome tônico pós-verbal;

(b) um pronome tônico pré-verbal;

(c) um pronome clítico pós-verbal (enclítico);

(d) um pronome clítico pré-verbal (proclítico).

Nas análises expressas nesses tableaux, o candidato (a) é o candidato ótimo. Isso, contudo, é problemático. Sabemos que esse é, de fato, o caso com os pronomes com características nominais - você, ele, a gente -, como mostramos nas análises da seção 3.2.1. E sabemos que esse também é o caso para muitos falantes do PB que usam formas como aquelas expressas pelos candidatos (a) dos Tableaux 8 a 10 - chamemos a essa variedade de dialeto 1. Entretanto, o que aparece nesses tableaux não reflete a gramática do nosso próprio dialeto - chamemos de dialeto 2. Ou seja: entre os candidatos (a) a (d) dos tableaux acima, o candidato ótimo (de acordo com nossa variedade, o dialeto 2) deveria ser o candidato (d). Foi isso o que mostramos em 3.1. No entanto, se estamos agora afirmando que candidatos como (a) e (b) competem com candidatos como (c) e (d), temos de conseguir demonstrar que, na gramática do nosso dialeto (o dialeto 2), o candidato (d) - e não (a) - seja o candidato ótimo.

“indicadores", no sentido laboviano; ou essas formas dão lugar a outras formas vernaculares não estigmatizadas (como você e a gente), que podem sincretizar os casos nominativo e acusativo. Estudos variacionistas têm apontado para esta última solução (cf. MONTEIRO, 1994; MENON, 1995; LOPES, 1999, 2007; ZILLES, 2002, 2005, 2007a, 2007b). 
Nossa proposta de análise com as restrições que elencamos até agora e com o ranqueamento que propusemos está dizendo o seguinte: se a competição dos candidatos a output envolver apenas clíticos, o candidato proclítico é o candidato ótimo; se a competição entre os candidatos envolver apenas pronomes tônicos, o candidato que respeitar a sequência SVO é o candidato ótimo. Contudo, gostaríamos de formalizar um ranqueamento gramatical que mostrasse como acontece quando há competição entre pronomes clíticos e pronomes plenos para o dialeto 2. Já mostramos, nos Tableaux 8 a 10, análises que representam um dialeto do PB que aceita formas como A Maria viu eu na festa ontem (o dialeto 1). Entretanto, temos de mostrar que há, de fato, dois dialetos no que diz respeito ao uso de pronomes em função de objeto direto em PB hoje. Além do dialeto 1, há um dialeto que não aceita frases como A Maria viu eu na festa ontem (mas aceita A Maria viu ele na festa ontem). Ou seja: o dialeto 2 aceita pronomes tônicos com características nominais em posição pós-verbal, mas não aceita que isso aconteça com pronomes de fato; nesse caso, temos de usar uma forma clítica em posição pré-verbal (A Maria me viu na festa ontem).

Com apenas duas restrições no ranqueamento, não conseguimos analisar os dados de maneira adequada; precisamos de outra restrição, que reflita o fato de que a gramática de alguns falantes não tolera pronomes nominativos em posição de objeto. Trata-se de uma restrição morfológica que reflete a condição de Elsewhere ou "princípio de Pānini" (ANDERSON, 1969; KIPARSKY, 1973; ARONOFF, 1976) ${ }^{18}$. Ou seja: o uso de uma forma mais específica se aplica antes de uma forma mais genérica.

Pronome Acusativo: a função de objeto direto é restrita ao pronome acusativo ${ }^{19}$.

Em outras palavras, se a língua (o dialeto 2, no caso) dispõe de uma forma pronominal marcada com caso acusativo, e se há uma função que exige um pronome especializado nessa forma, esse pronome deve ser favorecido, em detrimento de uma forma pronominal mais "geral” (ou menos específica). Essa restrição já é bem conhecida até mesmo pelos estudos gramaticais normativos de tradição latina (e que vemos em português e que deve influenciar o dialeto 2): os pronomes nominativos devem ser usados exercendo apenas a função sintática de sujeito, enquanto os acusativos devem ser empregados na função de objeto. Ou seja, o emprego de pronome não marcado morfologicamente em função acusativa acarreta obrigatoriamente uma violação. Vejamos como resolvemos o conflito nos tableaux abaixo.

Quem a Maria viu ontem?

\begin{tabular}{c|c|c|c} 
& DIRCL & ACUSATIVO & STAY \\
\hline a. A Maria viu eu. & & ${ }^{*} !$ & \\
\hline b. A Maria eu viu. & & ${ }^{*} !$ & \\
\hline c. A Maria viu-me. & ${ }^{*} !$ & & $*$
\end{tabular}

Tableau 11

No Tableau 11, vemos que o candidato ótimo é (d), pois viola apenas a restrição mais baixa no ranking. O mesmo acontece se reanalisarmos os Tableaux 9 e 10, agora com a restrição ACUSATIVO:

\footnotetext{
${ }^{18}$ Sobre a condição de Elsewhere em TO, remetemos o leitor a McCArthy $(2002,2011)$ e Prince e Smolensky (2004).

${ }^{19} \mathrm{Ou}$, de maneira mais formal: atribua uma marca de violação para cada pronome não acusativo em função de objeto direto. Como nos apontou Marcos Goldnadel (em comunicação pessoal): “[...] onde há marcação de caso (no português, apenas no sistema pronominal) a função sintática deve ser a que está relacionada com o caso” - Cf. também Wildner(2014).
} 
Quem a Maria viu ontem?

\begin{tabular}{c|c|c|c} 
& DIRCL & ACUSATIVO & STAY \\
\hline a. A Maria viu tu. & & ${ }^{*} !$ & \\
\hline b. A Maria tu viu. & & ${ }^{*} !$ & \\
\hline c. A Maria viu-te. & $* !$ & & $*$
\end{tabular}

Quem a Maria viu ontem?

\begin{tabular}{c|c|c|c} 
& DIRCL & ACUSATIVO & STAY \\
\hline a. A Maria viu nós. & & ${ }^{*} !$ & \\
\hline b. A Maria nós viu. & & ${ }^{\star} !$ & \\
\hline c. A Maria viu-nos. & ${ }^{\star} !$ & & ${ }^{\star}$ \\
\hline \multirow{2}{*}{ d. A Maria nos viu. } & \multicolumn{2}{|c}{ Tableau 13}
\end{tabular}

Ou seja, na competição de candidatos a expressar um objeto com pronomes de fato ( $e u, t u$, nós), o candidato ótimo aqui é aquele com o clítico correspondente, em posição proclítica. Esse ranqueamento representa a "gramática de colocação pronominal" do dialeto 2, proposta nesta análise:

\section{(17) DIRCL $>>$ ACUSATIVo $>>$ STAY}

Resta reanalisarmos aqueles casos em que o complemento verbal é um pronome com características nominais (vocêe, ele, a gente). Para esses casos, não usamos o clítico - você e a gente não têm correspondente pronominal clítico (talvez te e nos, por “empréstimo"). Para os pronomes de $3^{\text {a }}$ pessoa (ele, ela, eles, elas), é duvidável afirmar que contam com clíticos que fazem parte do vernáculo do $\mathrm{PB}$ no séc. XXI. Nesses casos, usamos o pronome tônico, como já mostramos em análises anteriores. Vejamos agora a análise com esses pronomes, com o ranqueamento que propusemos em (17).

Quem viu o João ontem?

\begin{tabular}{c|c|c|c} 
& DIRCL & ACUsativo & STAY \\
\hline b. A Maria viu ele. & & ${ }^{*}$ & \\
\hline b. Maria ele viu. & Tableau 14 & ${ }^{*}$ &
\end{tabular}

Quem a Maria viu ontem?

\begin{tabular}{c|c|c|c} 
& DiRCL & ACUSATIVo & STAY \\
\hline a. A Maria viu você. & & ${ }^{\star}$ & \\
\hline b. A Maria você viu. & Tableau 15 & ${ }^{\star}$ &
\end{tabular}

Quem a Maria viu ontem?

\begin{tabular}{c|c|c|c} 
& DIRCL & ACUSATIVO & STAY \\
\hline b. A Maria viu a gente. & & ${ }^{\star}$ & ${ }^{*} !$
\end{tabular}

Vemos que o ranqueamento proposto em (17) também consegue dar conta da análise dos casos em que não temos competição entre pronomes clíticos e tônicos. Repare que tanto o candidato (a), ótimo, como o (b) violam a restrição AcusaTivo. Contudo, o candidato ótimo não viola a restrição seguinte, STAY. É um caso de emergência do não-marcado em $\mathrm{TO}^{20}$. E o mais interessante é que

${ }^{20}$ Cf. Costa (2001), Mascaró (2004), McCarthy (2002, 2008). 
essa mesma solução de ranqueamento explica também o dialeto 1 , que não conta com clíticos pronominais. Ou seja, o ranqueamento proposto em (17) explica tanto a colocação pronominal do dialeto 2 quanto do dialeto 1 , que vimos anteriormente. Veja análises do dialeto 1 no tableau 17, abaixo, e compare com os tableaux (11) a (16), do dialeto 2.

Quem a Maria viu ontem?

\begin{tabular}{|c|c|c|c|}
\hline & DIRCL & Acusativo & STAY \\
\hline a. A Maria viu eultulvocêlele\nós\a genteleles. & & * & \\
\hline b. A Maria eu\tu\vocêlelelnós\a genteleles viu. & & ${ }^{\star !} !$ & * \\
\hline
\end{tabular}

Tableau 17

Como o dialeto 1 não conta com clíticos, explicamos formalmente por que os pronomes tônicos em função de complemento verbal aparecem depois do verbo: para respeitar o princípio de organização sintática básica da língua, expresso pela restrição $\mathrm{STAY}^{21}$.

Com isso, chegamos à definição do ranqueamento para as "gramáticas de colocação pronominal" nos dois dialetos de que tratamos (retomando aqui o ranqueamento que apresentamos em (17)):

$$
\text { DIRCL }>>\text { ACUSATIVO }>>\text { STAY }
$$

Acreditamos que apenas um desses dois dialetos irá se consolidar na língua, o dialeto 1. Apesar de encontrarmos o mesmo ranqueamento das condições gramaticais, a diferença entre os dialetos reside no fato de que, para os falantes do dialeto 1 , os pronomes clíticos não fazem parte de seu vernáculo e não participam de regras produtivas na língua ${ }^{22}$. Vários estudos (já mencionados) apontam justamente para o fato de que os pronomes clíticos estão em declínio em PB. Sendo assim, em se concretizando o dialeto 1, a restrição DIRCL não mais se justifica. E como os clíticos pronominais são, na verdade, formas acusativas, a restrição ACusativo também deixa de fazer sentido. Ou seja, em momentos futuros do PB, imaginamos que a estratégia de colocação pronominal siga apenas um único princípio de organização gramatical, STAY. Em outras palavras, como “ônus”, a língua passará a aceitar pronomes nominativos em função de objeto direto, ao passo que, como "bônus", a ordem da língua, mais uma vez, voltará a ser SVO, inclusive quando usamos pronomes.

\section{CONSIDERACÕES FINAIS}

Tentamos formalizar, neste artigo, a ideia de que, apesar de termos aparentemente variadas maneiras de usar pronomes com a função de objeto direto em PB, algumas poucas restrições estão atuando sobre o fenômeno e um mesmo ranqueamento pode dar conta de explicar essa aparente diversidade. Argumentamos, em última análise, que a gramática do PB busca privilegiar a ordem SVO, mesmo no dialeto que apresenta tratamento diferenciado para pronomes com características nominais (vocêe, ele, a gente) e para pronomes de fato $(e u, t u, n o ́ s)$. Afinal, apesar de o dialeto dispor de próclise, quando a colocação pronominal envolve um pronome do primeiro grupo, a estratégia é a colocação pronominal pós-verbal, com manutenção da ordem SVO da língua. Vimos que, em fases anteriores do PB, a ordem SVO já foi a predominante com o uso de pronomes - mas aí a ênclise garantia isso. Como fazer com que a ordem se mantenha SVO quando a língua começa a perder seus clíticos? A resposta que a própria gramática da língua está encontrando parece ser "use pronomes tônicos em ambas as funções: sujeito e objeto".

\footnotetext{
${ }^{21}$ Na verdade, cabe aqui uma observação pertinente de Marcos Goldnadel sobre o dialeto 1 (em comunicação pessoal): "Por que os falantes que dizem "viu tu" também dizem "te viu”? (Muitos dos falantes não fazem uso categórico do pronome depois do verbo.) Ou seja, por que há variação nesse grupo? Talvez pelo papel da escola e pelo próprio convívio com o outro grupo [falantes do dialeto 2], que ainda conta com clíticos)”. Ver também nota 22.

${ }^{22}$ Em caráter anedótico, podemos afirmar que, mesmo nós, falantes que usamos clíticos, somos surpreendidos ao usarmos pronomes de fato na função de objeto, por vezes.
} 


\section{REFERÊNCIAS}

ANDERSON, S. R. West Scandinavian vowel systems and the ordering of phonological rules. Tese de Doutorado. Massachusetts Institute of Technology, 1969.

ARONOFF, M. Word formation in generative grammar. Cambridge: MIT Press, 1976.

ARRUDA, N. C. A realização do objeto direto no português brasileiro culto falado: um estudo sincrônico. 2006. $201 f$. Dissertação (Mestrado) - Programa de Pós-graduação em Linguística e Língua Portuguesa, Universidade Estadual Paulista “Júlio de Mesquita Filho", Araraquara, 2006.

AYRES, M. R. Aspectos condicionadores do objeto nulo e do pronome pleno em português brasileiro: uma análise da fala infantil. 2016. 63f. Dissertação (Mestrado) - Programa de PósGraduação em Letras, Pontifícia Universidade Católica do Rio Grande do Sul, Porto Alegre, 2016.

AYRES, M. R.; OTHERO, G. A. Aspectos condicionadores do objeto nulo e do pronome pleno em português brasileiro: uma análise da fala infantil. Caderno de Squibs, Brasília, v. 2, n. 2, p. 1-12, 2016.

BAGNO, M. Gramática pedagógica do português brasileira. São Paulo: Parábola Editorial, 2011.

BASSO, R.; GONÇALVES, R. T. História concisa da língua portuguesa. Petrópolis: Vozes, 2014.

BRISOLARA, L. B. Os clíticos pronominais do português brasileiro e sua prosodização. Tese de Doutorado. Porto Alegre: PUCRS, 2008.

CAMARA JR., J. M. Ele como um acusativo no português do Brasil. In: Dispersos. Rio de Janeiro: FGV, 1972. p. 96-100.

CASTILHO, A. T. Nova gramática do português brasileiro. São Paulo: Contexto, 2010.

COSTA, J. The emergence of unmarked word order. In: LEGENDRE, G.; GRIMSHAW, J.; VIKNER, S. (Ed.). Optimality-theoretic syntax. Cambridge: MIT Press, 2001.p. 171-204.

CYRINO, S. M. L. O objeto nulo no português do Brasil: um estudo sintático-diacrônico. Tese de Doutorado. Campinas: Unicamp, 1994.

Observações sobre a mudança diacrônica no português do Brasil: objeto nulo e clíticos. In: ROBERTS, I.; KATO, M. A. (Org.). Português brasileiro: uma viagem diacrônica. Campinas: Ed. da Unicamp; 1996. p. 163-184.

O objeto nulo no português do Brasil: um estudo sintático-diacrônico. Londrina: UEL, 1997.

. Para a história do Português Brasileiro: a presença do objeto nulo e a ausência dos clíticos. Letras de Hoje, Porto Alegre, v. 38, n. 1, p. 31-47., 2003.

DRYER, M. Order of subject, object, and verb. In: HASPELMATH, M. et al. (Ed.). The world atlas of language structures. Oxford: Oxford University Press, 2005. p. 330-333.

Fórum linguistic., Florianópolis, v.14,n.1, p.1717-1734, jan./mar.2017. 
DUARTE, M. E. L. Clítico acusativo, pronome lexical e categoria vazia no português do Brasil. In: TARALLO, L. F. Fotografias sociolinguísticas. Campinas: Unicamp, 1989. p. 19-34.

FARACO, C. A. O tratamento você em português: uma abordagem histórica.-Fragmenta, Curitiba, n. 13, p. 51-82., 1996.

GALVES, C. O objeto nulo em português brasileiro: percurso de uma pesquisa. Cadernos de Estudos Linguísticos, Campinas, n. 17, p. 65-90, 1989.

Ensaios sobre as gramáticas do português. Campinas: Ed. da Unicamp, 2001.

GRIMSHAW, J.; SAMEK-LODOVICI, V. Optimal subjects and subject universals. In: BARBOSA, P. et al. (Ed.). Is the best good enough? Optimality and competition in syntax. Cambridge: MIT Press, 1998. p. 193-220.

KATO, M. A. Pronomes fortes e fracos na sintaxe do português brasileiro. Revista Portuguesa de Filologia, Coimbra,-v. XX, p. 101-122, 2002.

KENEDY, E. Curso básico de linguística gerativa. São Paulo: Contexto, 2013.

KIPARSKY, P. “Elsewhere” in phonology. In: ANDERSON, S. R.; KIPARSKY, P. A festschrift for Morris Halle. Holt: Rinehart and Winston, 1973. p 93-106.

LOPES, C. R. S. A inserção de a gente no quadro pronominal do português: percurso histórico. 1999. 181f. Tese (Doutorado) Faculdade de Letras, Universidade Federal do rio de Janeiro, Rio de Janeiro, 1999.

A inserção de 'a gente’ no quadro pronominal do português. Frankfurt am Main/Madrid: Vervuert/Iberoamericana, 2003.

. Pronomes pessoais. In: BRANDÃO, S. F.; VIEIRA, S. R. (Org.). Ensino de gramática: descrição e uso. São Paulo: Contexto, 2007.p. 103-120.

MASCARÓ, J. External allomorphy as emergence of the unmarked. In: McCARTHY, J. Optimality theory in phonology: a reader. Oxford: Blackwell, 2004. p. 513-522.

MCCARTHY, J. A thematic guide to Optimality Theory. Cambridge: Cambridge University Press, 2002.

Doing optimality theory: applying theory to data. Oxford: John Wiley \& Sons, 2011.

; PRINCE, A. Prosodic morphology I: constraint interaction and satisfaction. Manuscrito, University of Massachusetts, Amherst, e Rutgers University, New Brunswick, N. J., 1993.

MENON, O. S. P. O sistema pronominal do português. Revista Letras, Curitiba, n. 44, 1995.

MONTEIRO, J. L. Pronomes pessoais. Fortaleza: EUFC, 1994. 
NEVES, M. H. M. Gramática de usos do português. São Paulo: Unesp, 2000.

NUNES, J. M. Direção de cliticização, objeto nulo e pronome tônico na posição de objeto em português brasileiro. In: ROBERTS, I.; KATO, M. (Org.). Português brasileiro: uma viagem diacrônica. Campinas: Unicamp, 1996. p. 207-222.

OMENA, N. P. de. Pronome pessoa de terceira pessoal: suas formas variantes em função acusativa. 1978. Dissertação (Mestrado) - Pontifícia Universidade Católica do Rio de Janeiro, Rio de Janeiro, 1978.

OMENA, N. P. de. A referência variável da primeira pessoa do discurso no plural. In: NARO, A. et al. Relatório final de pesquisa: projeto subsídios do projeto censo à educação. Rio de Janeiro, UFRJ, v. 2, 1986. p. 286-329.

OTHERO, G. A.; MENUZZI, S. M. Distribuição de elementos leves dentro do VP em português: interação entre sintaxe, prosódia e estrutura informacional em Teoria da Otimidade. Fórum Linguístico, Florianópolis, v. 6, n. 1, p.23-44, 2009.

; FIGUEIREDO SILVA, M. C. Focalização em português: interface entre condições sintáticas, prosódicas e de estrutura informacional. In: CRUZ, R. T. (Org.). As interfaces da gramática. Curitiba: CRV, 2012. p. 119-135.

OTHERO, G. A.; AYRES, M. R.; SCHWANKE, C.; SPINELLI, A. C. A relevância do traço gênero semântico na realização do objeto nulo em português brasileiro. Working Papers em Linguística, Florianópolis, v. 17, n.1, p. 64-86, 2016.

OTHERO, G. A.; SCHWANKE, C. Retomadas anafóricas de objeto direto em português brasileiro escrito. [A sair].

OTHERO, G. A.; SPINELLI, A. C. Analisando a retomada anafórica do objeto direto em português falado. [A sair].

PAGOTTO, E. G. A posição dos clíticos em português - um estudo diacrônico. Tese de Doutorado. Campinas: Unicamp, 1993. Clíticos, mudança e seleção natural. In: ROBERTS, Ian; KATO, Mary (Org.). Português brasileiro: uma viagem diacrônica. Campinas: Unicamp, 1996. p. 185-206.

PEREIRA, M. G. D. A variação na colocação dos pronomes átonos no português do Brasil. Dissertação de Mestrado. Rio de Janeiro: PUCRJ, 1981.

PERINI, M. A. Modern Portuguese: a reference grammar. Yale University Press, 2002.

Gramática descritiva do português brasileiro. Petrópolis: Vozes, 2016.

PRINCE, A.; SMOLENSKY, P. Optimality theory: constraint interaction in Generative Grammar. RuCCs Technical Report 2 , Rutgers University Center for Cognitive Science, Piscataway, N. J., 1993.

. Optimality Theory: constraint interaction in generative grammar. In: McCARTHY, J. Optimality theory in phonology: a reader. Oxford: Blackwell, 2004.

SCHWENTER, S.; SILVA, G. Overt vs. null direct objects in spoken Brazilian Portuguese: a semantic/pragmatic account. Hispania, v. 85, n.3, 2002.

VIEIRA, S. R. Colocação pronominal nas variedades européia, brasileira e moçambicana: para a definição da natureza do clítico em português. 2002. 441f. Tese (Doutorado). Facultade de Letras, Universidade Federal do Rio de Janeiro, Rio de Janeiro, 2002. 
VIEIRA, S. R. A ordem dos clíticos em lexias verbais simples nas variedades brasileira, européia e moçambicana do português. In: ENCONTRO DO CELSUL, 5., 2003, Curitiba. Anais... Curitiba, UFPR, 2003. VIEIRA-PINTO, C. A.; COELHO, I. L. O objeto direto anafórico de SN: uma análise da fala de Florianópolis em duas sincronias. ReVEL, edição especial n. 13, p. 245-263, 2016.

VITRAL, L. A forma cê e a noção de gramaticalização. Revista de Estudos da Linguagem, Campinas, v. 5, n.4, 1996.

WILDNER, R. A ordem pronominal do português brasileiro: uma análise via Teoria da Otimidade. 2014. 150f. Dissertação (Mestrado). Instituto de Letras, Universidade Federal do Rio Grande do Sul, Porto Alegre, 2014.

ZILLES, A. M. S. Grammaticalization of 'a gente' in Brazilian Portuguese. Working Papers in Linguistics, Florianópolis, v. 8, n. 3, 2002.

ZILLES, A. M. S. The development of a new pronoun: the linguistic and social embedding of 'a gente' in Brazilian Portuguese. Language Variation and Change, Cambridge, v. 17, n. 1, 2005.

Grammaticalization of a gente as a cluster of changes: evidence from apparent and real time studies. Fórum Linguístico, Florianópolis, v. 4, 2007a.

. O que a fala e a escrita nos dizem sobre a avaliação social do uso de a gente? Letras de Hoje, Porto Alegre, v. 42, p.27-44, 2007b. 